\title{
Homozygous carriers of the $G$ allele of rs4664447 of the glucagon gene ( $G C G)$ are characterised by decreased fasting and stimulated levels of insulin, glucagon and glucagon-like peptide (GLP)-1
}

\author{
S. S. Torekov • L. Ma • N. Grarup • B. Hartmann • I. A. Hainerová • U. Kielgast • H. Kissow • \\ M. Rosenkilde • GIANT Consortium • J. Lebl • D. R. Witte • T. Jørgensen • A. Sandbaek • \\ T. Lauritzen • O. D. Madsen • J. Wang • A. Linneberg • \\ S. Madsbad • J. J. Holst • T. Hansen • O. Pedersen
}

Received: 19 April 2011 / Accepted: 1 July 2011 /Published online: 7 August 2011

(C) Springer-Verlag 2011

\begin{abstract}
Aims/hypothesis The glucagon gene (GCG) encodes several hormones important for energy metabolism: glucagon, oxyntomodulin and glucagon-like peptide (GLP)-1 and -2. Variants in $G C G$ may associate with type 2 diabetes, obesity and/or related metabolic traits.

Methods GCG was re-sequenced as a candidate gene in 865 European individuals. Twenty-nine variants were identified. Four variants that were considered to have a likelihood for altered functionality: rs4664447, rs7581952, Ile158Val and Trp169Ter, were genotyped in 17,584 Danes. Results When examined in 5,760 treatment-naive individuals, homozygous carriers of the low frequency (minor allele
\end{abstract}

Electronic supplementary material The online version of this article (doi:10.1007/s00125-011-2265-7) contains peer-reviewed but unedited supplementary material, including a list of the GIANT Consortium members, which is available to authorised users.

S. S. Torekov $\cdot$ B. Hartmann $\cdot$ H. Kissow $\cdot$ J. J. Holst $\cdot$ O. Pedersen Department of Biomedical Sciences, Faculty of Health Sciences,

University of Copenhagen,

2200 Copenhagen, Denmark

S. S. Torekov $(\triangle) \cdot N$. Grarup $\cdot$ B. Hartmann $\cdot$ H. Kissow $\cdot$

J. J. Holst $\cdot$ T. Hansen $\cdot$ O. Pedersen

The Novo Nordisk Foundation Center for Basic Metabolic Research,

Faculty of Health Sciences, University of Copenhagen,

Copenhagen, Denmark

e-mail: Torekov@sund.ku.dk

L. Ma $\cdot$ J. Wang

Beijing Genomics Institute at Shenzhen,

Shenzhen, People's Republic of China frequency $2.3 \%$ ) G allele of rs4664447, predicted to disrupt an essential splice enhancer binding site, had lower levels of fasting plasma glucose (mean $\pm \mathrm{SD}, 4.8 \pm 1.2$ vs $5.5 \pm$ $0.8 \mathrm{mmol} / \mathrm{l}, p=0.004)$; fasting serum insulin $(22 \pm 14$ vs $42 \pm 27 \mathrm{pmol} / 1, p=0.04$ ); glucose-stimulated serum insulin $(159 \pm 83$ vs $290 \pm 183 \mathrm{pmol} / \mathrm{l}, p=0.01)$ and adult height ( $165 \pm 10$ vs $172 \pm 9 \mathrm{~cm}, p=0.0009)$ compared with A allele carriers. During oral glucose tolerance and hyperglycaemic arginine stimulation tests, the plasma AUC for GLP-1 ( $730 \pm 69$ vs $1,334 \pm 288 \mathrm{pmol} / 1 \times \min , p=0.0002)$ and basal and stimulated levels of serum insulin and plasma glucagon were $\sim 50 \%$ decreased $(p<0.001)$ among three homozygous carriers compared with nine matched wild-type

I. A. Hainerová · J. Lebl

Department of Paediatrics, Charles University,

Prague, Czech Republic

U. Kielgast $\cdot$ S. Madsbad

Department of Endocrinology, Hvidovre University Hospital, Hvidovre, Denmark

M. Rosenkilde

Department of Neuroscience and Pharmacology,

Faculty of Health Sciences, University of Copenhagen,

Copenhagen, Denmark 
carriers. rs7581952, Ile158Val and Trp169Ter (where 'Ter' indicates 'termination') variants of GCG did not significantly associate or co-segregate with the metabolic traits examined. Conclusions/interpretation Re-sequencing of GCG revealed a low frequency intronic variant, rs4664447, and follow-up physiological studies suggest that this variant in homozygous form may cause decreased fasting and stimulated levels of insulin, glucagon and GLP-1. Overall, our findings suggest that variation in GCG has no major impact on carbohydrate metabolism in the study populations examined.

Keywords Genetics of type 2 diabetes · Insulin secretion in vivo · Insulin sensitivity and resistance · Islets · Metabolic physiology in vivo $\cdot$ Monogenic forms of diabetes

\section{Abbreviations \\ AIR Acute insulin response \\ GLP Glucagon-like peptide \\ GWAS Genome-wide association studies \\ MAF Minor allele frequency \\ SNP Single nucleotide polymorphism}

\section{Introduction}

For the past several years most studies of the genetics of obesity and type 2 diabetes have been based on the HapMap resource of sequence variation [1], forming the basis for genome-wide association studies (GWAS). While HapMap

D. R. Witte

Steno Diabetes Center,

Gentofte, Denmark

T. Jørgensen $\cdot$ A. Linneberg

Research Centre for Prevention and Health,

Glostrup University Hospital,

Glostrup, Denmark

A. Sandbaek $\cdot$ T. Lauritzen

Department of General Practice, University of Aarhus,

Aarhus, Denmark

O. D. Madsen $\cdot$ T. Hansen $\cdot$ O. Pedersen

Hagedorn Research Institute,

Gentofte, Denmark

T. Hansen

Faculty of Health Sciences, University of Southern Denmark,

Odense, Denmark

O. Pedersen

Faculty of Health Sciences, University of Aarhus,

Aarhus, Denmark

GIANT consortium

URL: www.helmholtz-muenchen.de/epi/arbeitsgruppen/genetische-

epidemiologie/projects-projekte/giant-consortium/index.html offers good proxies for most common single nucleotide polymorphisms (SNPs) with a frequency above $5 \%$, the coverage rapidly declines for alleles with lower frequency [2]. In order to identify disease-associated low frequency and rare variants, we need to re-sequence the genes or, ideally, the whole genome in thousands of cases and controls. The glucagon gene $(G C G)$ located on chromosome $2 \mathrm{q} 24.2$ consists of six exons and encodes several proteins crucial for energy metabolism, i.e. glucagon, glucagon-like peptide (GLP)-1 and -2, and oxyntomodulin [3]. To date no study on large-scale sequencing of $G C G$ has been published. In light of the crucial role of $G C G$ in energy metabolism, we hypothesised that low frequency variants of $G C G$ are associated with diabetes, obesity and/or related metabolic intermediary quantitative traits. Therefore, we performed a large-scale candidate gene study of $G C G$.

\section{Methods}

$D N A$ analysis of $G C G$ Genomic DNA was isolated from human leucocytes using standard methods. Primer3 was used to design primers targeting the coding, exon-intron boundary, and conserved regions of GCG (NCBI: X03991, gi31786). The conserved regions were selected by satisfying: (1) BlastN E-value $<1 \times 10^{-20}$; (2) length $>100 \mathrm{bp}$; (3) existence of homology sequences at least in two of Bos taurus, Rattus norvegicus, Mus musculus and Gallus gallus. Nine segments were obtained by PCR amplifier, corresponding to six exons (plus the exon-intron boundary) and three conserved regions (Table 1). The amplified samples were subject to multiple direct sequencing using an ABI 3730 platform (Life Technologies, Carlsbad, CA, USA) following the standard protocol advised by the manufacturer. The sequences of the nine fragments were aligned together, and PolyPhred [4] and Consed [5] were employed to detect variants among samples. Variants were considered true when consensus was obtained between multiple repeated sequenced samples. Genotyping of the polymorphisms was performed using KASPar allelic discrimination (KBioscience, Hoddesdon, UK). Discordance between 1,479 random duplicate samples was $0 \%$ and the genotyping success rate was $>99.5 \%$ for all variants. All variants obeyed Hardy-Weinberg equilibrium $(p>0.2)$.

Study population for mutation detection

1. In order to identify low frequency SNPs in the general population, $G C G$ was re-sequenced in 384 randomly selected unrelated middle-aged Danish individuals, $45 \%$ men, aged $45 \pm 7$ years, BMI $26.8 \pm 5.0 \mathrm{~kg} / \mathrm{m}^{2}$, randomly recruited in the Inter99 study [6]; 35 of these individuals had type 2 diabetes. 
Table $1 G C G$ variants discovered in 865 European individuals

\begin{tabular}{|c|c|c|c|c|c|c|c|c|}
\hline $\begin{array}{l}\text { SNP } \\
\text { no. }\end{array}$ & $\begin{array}{l}\text { Variant identified } \\
\text { in amplicon }{ }^{\mathrm{b}} \\
\text { containing }\end{array}$ & rs number & $\begin{array}{l}\text { Genomic position } \\
\text { (NCBI Build 37) }\end{array}$ & $\begin{array}{l}\text { Location relative } \\
\text { to exons }\end{array}$ & $\begin{array}{l}n \\
\text { participants }\end{array}$ & $\begin{array}{l}\text { Heterozygous } \\
\text { frequency }(\%)\end{array}$ & $\begin{array}{l}\text { Identified } \\
\text { in study } \\
\text { group }\end{array}$ & $\begin{array}{l}\text { Predicted } \\
\text { functionality } \\
\text { score }(1[\mathrm{low}]-5 \\
\text { [high] })\end{array}$ \\
\hline
\end{tabular}

\begin{tabular}{|c|c|c|c|c|c|c|c|c|}
\hline 1 & Conserved region 1 & & 163006577 & $-1052 \mathrm{~A} / \mathrm{G}$ rel. ATG site & 6 & 0.7 & 1 & 1 \\
\hline 2 & Conserved region 1 & & 163006519 & $-827 \mathrm{~T} / \mathrm{C}$ rel. ATG site & 1 & 0.1 & 1 & 1 \\
\hline 3 & Conserved region 1 & & 163006515 & $-827 \mathrm{G} / \mathrm{A}$ rel. ATG site & 2 & 0.2 & 2 and 3 & 1 \\
\hline 4 & Conserved region 1 & & 163006150 & $-462 \mathrm{G} / \mathrm{A}$ rel. ATG site & 2 & 0.2 & 1 and 3 & 1 \\
\hline 5 & Conserved region 1 & & 163006000 & $-312 \mathrm{~A} / \mathrm{T}$ rel. ATG site & 1 & 0.1 & 1 & 1 \\
\hline 6 & Conserved region 1 & & 163005875 & $-186 \mathrm{~A} / \mathrm{G}$ rel. ATG site & 1 & 0.1 & 1 & 1 \\
\hline 7 & Exon 2 & rs5645/rs13306376 & 163005674 & Tyr5Tyr & 50 & 5.8 & $1-4$ & 1 \\
\hline 8 & Exon 2 & & 163005649 & Leu14Leu C/T & 1 & 0.1 & 2 & 1 \\
\hline 9 & Conserved region 2 & & 163004525 & $-501 \mathrm{~T} / \mathrm{G}$ rel. exon 3 & 1 & 0.1 & 1 & 1 \\
\hline 10 & Conserved region 2 & & 163004459 & $-4358 \mathrm{G} / \mathrm{A}$ rel. exon 3 & 1 & 0.1 & 3 & 1 \\
\hline 11 & Conserved region 2 & & 163004410 & $-4407 \mathrm{~T} / \mathrm{C}$ rel. exon 3 & 1 & 0.1 & 2 & 1 \\
\hline 12 & Conserved region 2 & & 163004291 & $-255 \mathrm{G} / \mathrm{A}$ rel exon 3 & 1 & 0.1 & 2 & 1 \\
\hline 13 & Exon3 & & 163003985 & Pro44Pro T/C & 1 & 0.1 & 1 & 1 \\
\hline 14 & Exon3 & rs 11552330 & 163003961 & Arg52Arg & 1 & 0.1 & 1 & 1 \\
\hline 15 & Exon3 & rs5649 & 163003858 & +5 rel. exon 3 & 4 & 0.5 & 1 & 1 \\
\hline 16 & Conserved region 3 & rs $4664447^{\mathrm{a}}$ & 163003191 & $+671 \mathrm{~A} / \mathrm{G}$ rel. exon 3 & 50 & 5.8 & $1-4$ & 4 \\
\hline 17 & Conserved region 3 & & 163003173 & $+689 \mathrm{G} / \mathrm{A}$ rel. exon3 & 1 & 0.1 & 3 & 1 \\
\hline 18 & Exon 4 & & 163002256 & $-71 \mathrm{~T} / \mathrm{C}$ rel exon 4 & 20 & 2.3 & $1-3$ & 1 \\
\hline 19 & Exon 4 & & 163001920 & $+128 \mathrm{G} / \mathrm{A}$ rel. exon 4 & 1 & 0.1 & 1 & 1 \\
\hline 20 & Exon 4 & & 163001905 & $+143 \mathrm{~T} / \mathrm{A}$ rel. exon 4 & 1 & 0.1 & 4 & 1 \\
\hline 21 & Exon 5 & rs $7581952^{\mathrm{a}}$ & 163000856 & $-176 \mathrm{~T} / \mathrm{G}$ rel. Exon 5 & 44 & 5.1 & $1-4$ & 2 \\
\hline 22 & Exon 5 & & 163000768 & $-88 \mathrm{~A} / \mathrm{G}$ rel. exon 5 & 1 & 0.1 & 1 & 1 \\
\hline 23 & Exon 5 & & 163000601 & Ile158 $\mathrm{Val}^{\mathrm{a}}$ & 2 & 0.2 & 1 & 4 \\
\hline 24 & Exon 5 & & 163000564 & Trp169Ter ${ }^{\mathrm{a}}$ & 1 & 0.1 & 4 & 5 \\
\hline 25 & Exon 5 & & 163000460 & $+73 \mathrm{C} / \mathrm{T}$ rel. exon 5 & 1 & 0.1 & 2 & 1 \\
\hline 26 & Exon 5 & & 163000351 & $+192 \mathrm{G} / \mathrm{T}$ rel. exon 5 & 1 & 0.1 & 1 & 1 \\
\hline 27 & Exon 5 & & 163000307 & $+226 \mathrm{~A} / \mathrm{G}$ rel. exon 5 & 1 & 0.1 & 2 & 1 \\
\hline 28 & Exon 5 & & 163000301 & $+232 \mathrm{~A} / \mathrm{G}$ rel. exon 5 & 4 & 0.5 & 1,2 and 4 & 1 \\
\hline 29 & Exon 6 & & 162999704 & $+175 \mathrm{~T} / \mathrm{A}$ rel exon 6 & 1 & 0.1 & 1 & 1 \\
\hline
\end{tabular}

The individuals were from the following study groups: (1) 384 middle-aged Danish people randomly picked from Inter99; (2) 289 obese Czech children; (3) 96 obese adult Danes; and (4) 86 Danish and 10 Czech patients with early-onset non-autoimmune diabetes rs5645 and rs4664447 were in complete LD $\left(r^{2}=1.0\right)$

${ }^{a}$ Variants selected for large-scale genotyping

${ }^{\mathrm{b}}$ Coordinates of amplicons (relative to X03991): exon 1, 535-698; conserved region 1, 2,840-3,500; exon 2, 3,289-3,770; conserved region 2, 4,841-5,244; exon 3, 5,262-5,603; conserved region 3, 5,810-6,400; exon 4, 7,043-7,476; exon 5, 8,683-8,826; exon 6, 9,481-10,050. No variants were detected in exon 1 . The genomic position on chromosome 2 is from NCBI Build 37

2. In order to identify $G C G$ variants potentially associated with early-onset obesity, $G C G$ was re-sequenced in 289 (157 girls, 132 boys) Czech children and adolescents with early-onset obesity aged 1-18 years. Early-onset obesity was defined as obesity observed before the age of 11 years and with BMI (kilograms per square metre), retrospectively evaluated, exceeding the 97 th percentile for sex and age according to Czech national references. The mean age at obesity onset was $4.9 \pm 3.1$ years (range $0.5-11.0$ years) [7].
3. In order to identify $G C G$ variants potentially associated with inheritance of adult-onset obesity and type 2 diabetes, $G C G$ was re-sequenced in 96 (50 women, 46 men) obese Danish individuals, aged $50 \pm 15$ years, BMI $36.4 \pm 5.1 \mathrm{~kg} / \mathrm{m}^{2}$, all recruited from obese families with type 2 diabetes at Steno Diabetes Center in Copenhagen.

4. In order to identify $G C G$ variants potentially associated with inheritance of early-onset diabetes, $G C G$ was resequenced in 86 Danish and 10 Czech patients (55 
women, 41 men) with onset of diabetes before the age of 40 and with a family history of diabetes. None of the patients had mutations in any of the known MODY genes (MODY1-6); age $35 \pm 10$ years, age of onset $25 \pm$ 5 years, BMI $26.0 \pm 5 \mathrm{~kg} / \mathrm{m}^{2}$.

Bioinformatics analyses and selection of variants for largescale genotyping Functionality of all identified variants was predicted by FastSNP [8] and ESEFinder [9]. Variants were scored from 1 (low predicted functionality) to 5 (high predicted functionality) (Table 1). Based upon functionality predictions, we chose to genotype rs4664447 (predicted functionality 4, minor allele frequency [MAF] 2.4\%), rs7581952 (predicted functionality 2, MAF 2.3\%), Ile158Val (predicted functionality 4, MAF $0.2 \%$ ) and Trp169Ter ('Ter' indicates 'termination'; predicted functionality 5 , very rare) in 17,584 Danes and to analyse for genotype-trait relationships.

In the initial screening of the 384 randomly selected individuals from Inter99, rs4664447 and rs5645 were in complete linkage disequilibrium (LD) $\left(r^{2}=1\right)$.

Study population for large-scale genotyping Trp169Ter, Ile158Val, rs7581952, and rs4664447 were genotyped in 17,584 Danish individuals comprising the following.

1. The Inter99 sample of randomly collected middle-aged Danish individuals examined at the Research Centre for Prevention and Health [6], $n=6,204,3,070$ men, 3,094 women, age $46 \pm 8$ years, BMI $26.3 \pm 4.6 \mathrm{~kg} / \mathrm{m}^{2}$ ). The Inter99 study (ClinicalTrials.gov NCT00289237) is a randomised multi-factorial intervention study aiming at changing lifestyle to prevent cardiovascular disease and diabetes in a free-living population examined over a 5year period.

2. A randomly recruited group of middle-aged glucosetolerant participants examined at Steno Diabetes Center $(n=521,244$ men, 277 women, age $57 \pm 10$ years, BMI $\left.25.8 \pm 3.7 \mathrm{~kg} / \mathrm{m}^{2}\right)$.

3. Type 2 diabetes patients sampled through the outpatient clinic at Steno Diabetes Center $(n=1,820,1,117$ men, 703 women, age $61 \pm 11$ years, BMI $30.3 \pm 5.5 \mathrm{~kg} / \mathrm{m}^{2}$ ).

4. The ADDITION (Anglo-Danish-Dutch Study of Intensive Treatment and Complication Prevention in Type 2 Diabetic Patients Identified by Screening in Primary Care) Denmark screening cohort $(n=8,662,4,729$ men, 3,933 women, age $60 \pm 7$ years, BMI $28.6 \pm 4.9 \mathrm{~kg} / \mathrm{m}^{2}$ ) sampled by the Department of General Practice at the University of Aarhus [10]. The ADDITION Denmark screening cohort (ClinicalTrials.gov NCT00237548) includes participants who were recruited via a stepwise strategy based on a risk questionnaire followed by measurements of random blood glucose, $\mathrm{HbA}_{1 \mathrm{c}}$, and fasting and OGTT plasma glucose to clinically diagnose diabetes.
5. A randomly recruited sample of young healthy participants recruited from the Steno Diabetes Centre (Gentofte, Denmark): UNG92 ( $n=377,186$ men, 191 women, age $25 \pm 4$ years, BMI $23.6 \pm 3.7 \mathrm{~kg} / \mathrm{m}^{2}$ ) [11].

Study groups 1 and 2 underwent a standard $75 \mathrm{~g}$ OGTT, and study group 5 underwent an IVGTT in combination with tolbutamide stimulation as described [11].

Case-control studies of type 2 diabetes were carried out in 3,778 type 2 diabetes patients $(1,820$ patients recruited at Steno Diabetes Center, 340 patients from the Inter99 cohort, and 1,618 patients from the Danish ADDITION Study) and 5,043 glucose-tolerant participants (521 individuals recruited at Steno Diabetes Center and 4,522 individuals from Inter99). Studies of quantitative glucose related traits were carried out in treatment-naive individuals from the Inter99 Study, excluding the 340 patients diagnosed with and treated for type 2 diabetes. Case $\left(\mathrm{BMI} \geq 30 \mathrm{~kg} / \mathrm{m}^{2}\right) /$ control $\left(\mathrm{BMI}<25 \mathrm{~kg} / \mathrm{m}^{2}\right)$ studies of obesity and studies of quantitative obesity-related traits were performed in the pooled combined study sample of 17,584 Danish individuals.

The actual number of individuals genotyped for each variant is given in the respective tables. There was no overlap between sequenced study samples and genotyped study samples, apart from the 384 randomly selected individuals from the Inter99 Study. Informed written consent was obtained from all individuals before participation. The study was approved by the Ethical Committee of Copenhagen County and was in accordance with the principles of the Helsinki Declaration. Type 2 diabetes was defined according to the WHO recommendations [12].

Biochemical and anthropometric measures Height and body weight were measured while participants were wearing light indoor clothes and without shoes, and BMI was calculated as weight in kilograms/(height in metres) ${ }^{2}$. Waist circumference was measured in the standing position midway between the iliac crest and the lower costal margin. Blood samples were drawn after a $12 \mathrm{~h}$ overnight fast. Plasma glucose was measured by a glucose oxidase method (Granutest; Merck, Darmstadt, Germany) with a detection limit of $0.11 \mathrm{mmol} / 1$ and intra- and inter-assay coefficients of variation of $<0.8 \%$ and $<1.4 \%$, respectively. Radioimmunological determination of fully processed glucagon was performed using a specific assay as described [13]. The analytical detection limit was $1 \mathrm{pmol} / 1$ and intra- and interassay coefficients of variation were $<6 \%$ and $<15 \%$, respectively. Total plasma GLP-1 was assayed by radioimmunoassay as described previously [14]. The assay has a detection limit of $1 \mathrm{pmol} / 1$ and intra- and inter-assay coefficients of variation are $<6 \%$ and $<15 \%$, respectively. Serum insulin [excluding des $(31,32)$ and intact proinsulin] 
was measured using the AutoDELFIA insulin kit (PerkinElmer, Wallac, Turku, Finland). Total intra- and inter-assay coefficients of variation were $<3.2 \%$ and $4.5 \%$, respectively. The analytical detection limit was $3 \mathrm{pmol} / \mathrm{l}$.

Methods for additional physiological characterisation of rs4664447 carriers Three participants (two men and one woman, age $50-65$ years, BMI $18.6-25.9 \mathrm{~kg} / \mathrm{m}^{2}$ ) who were homozygous carriers of rs4664447 were available for additional phenotype studies. For each carrier, three BMI, age and sex matched controls (wild-type carriers) (nine in total, three women, six men, mean age $54 \pm 7$ years, mean BMI $24.7 \pm 3.3 \mathrm{~kg} / \mathrm{m}^{2}$ ) were invited for additional metabolic characterisation at the Steno Diabetes Center.

Oral glucose tolerance test After an overnight fast, blood samples for measurement of plasma glucose, serum insulin, serum C-peptide, plasma GLP-1 and plasma glucagon were taken prior to a standard $75 \mathrm{~g}$ OGTT. Blood sampling was repeated every $15 \mathrm{~min}$ until $180 \mathrm{~min}$ after the start of the OGTT.

Glucose-dependent arginine stimulation test The test was performed as described [15] and used to measure the acute insulin and glucagon responses to intravenous arginine injection at the fasting plasma glucose level and at glucose concentrations clamped at 14 and at $25 \mathrm{mmol} / 1$, respectively. After an overnight fast, blood samples for measurement of serum insulin, serum C-peptide, plasma GLP-1, and plasma glucagon were taken prior to arginine injection and eight times during the following $30 \mathrm{~min}$ in the fasting state and with glucose concentrations clamped at 14 and at $25 \mathrm{mmol} / \mathrm{l}$, respectively. There was a $2.5 \mathrm{~h}$ resting period between the clamps at 14 and at $25 \mathrm{mmol} / \mathrm{l}$ of plasma glucose.

Statistical analysis Case-control studies were performed by applying logistic regression including adjustments for sex, age and BMI (for type 2 diabetes analyses) to examine differences in genotype distributions between affected and unaffected individuals. Studies of the Ile158Val variant were calculated for the dominant model (wild-type vs heterozygote+homozygote, where wild-type is the major allele), as it was too rare to calculate the OR for the additive and recessive model. The recessive model (wild-type+ heterozygote vs homozygote), was chosen relevant for the other variants. The additive model was added as a reference in comparison with the studies in large consortia as these only show additive models. To test for quantitative trait differences between genotype groups, a general linear model was used including adjustments for sex, age and BMI when appropriate. We did not find any evidence of population stratification when we applied 39 unlinked markers using the Structure program [16]. Furthermore, we did not detect any evidence of population stratification among the study groups in the data set when adjusting for the first principal component of Eigenstrat analysis among 11,150 individuals on whom we have sufficient SNP data to perform Eigenstrat analysis [17]. Consequently, the study groups were pooled for analysis. The incremental AUC was calculated using the trapezoidal method. Insulinogenic index and HOMA-IR were calculated as described [18]. During the OGTT, the disposition index was calculated as insulinogenic index/HOMA-IR and during the intravenous arginine stimulation test, the disposition index was calculated as acute insulin response to arginine stimulation (0$10 \mathrm{~min})\left(\mathrm{AIR}_{0-10 \text { arginine}}\right) / \mathrm{HOMA}-\mathrm{IR}$. Analyses were performed with RGui version 2.8.0 and GraphPad Prism 5. Statistical power estimations of case-control studies were calculated in CaTS power calculator, version 0.02 (www. sph.umich.edu/csg/abecasis/CaTS/index.html) and power estimations of quantitative traits analyses were calculated in PS power and sample size calculation version 3.0.34 (http:// ps-power-and-sample-size-calculation.software.informer. com/download). Taking Bonferroni correction into consideration (which is conservative in this case given the correlation among the traits) leads to a significance level of $p=0.0012$. Thus, only $p$ values of 0.001 or less were considered significant.

\section{Results}

By re-sequencing $G C G$ in 853 Europeans, many of whom had type 2 diabetes or were obese, we identified 29 different variants (Table 1). Four variants with a considered likelihood for altered functionality: rs4664447, rs7581952, Ile158Val and Trp169Ter were selected for large-scale genotyping in a total of 17,584 Danish individuals and investigated for association with obesity, type 2 diabetes and metabolic traits (Fig. 1).

rs4664447 was not associated with type 2 diabetes (Table 2). However, homozygous carriers of the $\mathrm{G}$ allele of rs4664447 had lower fasting plasma glucose, lower fasting and oral glucose-stimulated serum insulin, lower insulinogenic index, lower HOMA-IR, higher Matsuda's insulin sensitivity, normal disposition index and shorter adult height compared with A allele carriers when analysed in 5,760 treatment-naive middle-aged individuals from the Inter99 cohort (Table 3). With four GG carriers and 5756 $\mathrm{AA}$ and $\mathrm{AG}$ carriers and a difference in fasting mean serum insulin of $20 \mathrm{pmol} / \mathrm{l}$ insulin and a standard deviation of 14 we have a statistical power of $82 \%, p<0.05$. The association with lower fasting plasma glucose was even stronger when the analyses were restricted to the 4,370 glucose-tolerant people of Inter99, (AA, $5.3 \pm 0.4+$ AG, 5.3 \pm 0.4 vs GG, $4.8 \pm 1.1 \mathrm{mmol} / 1$ glucose $p_{\text {rec }}=0.00004$, where $p_{\text {rec }}$ is the $p$ value for the recessive model). During an 


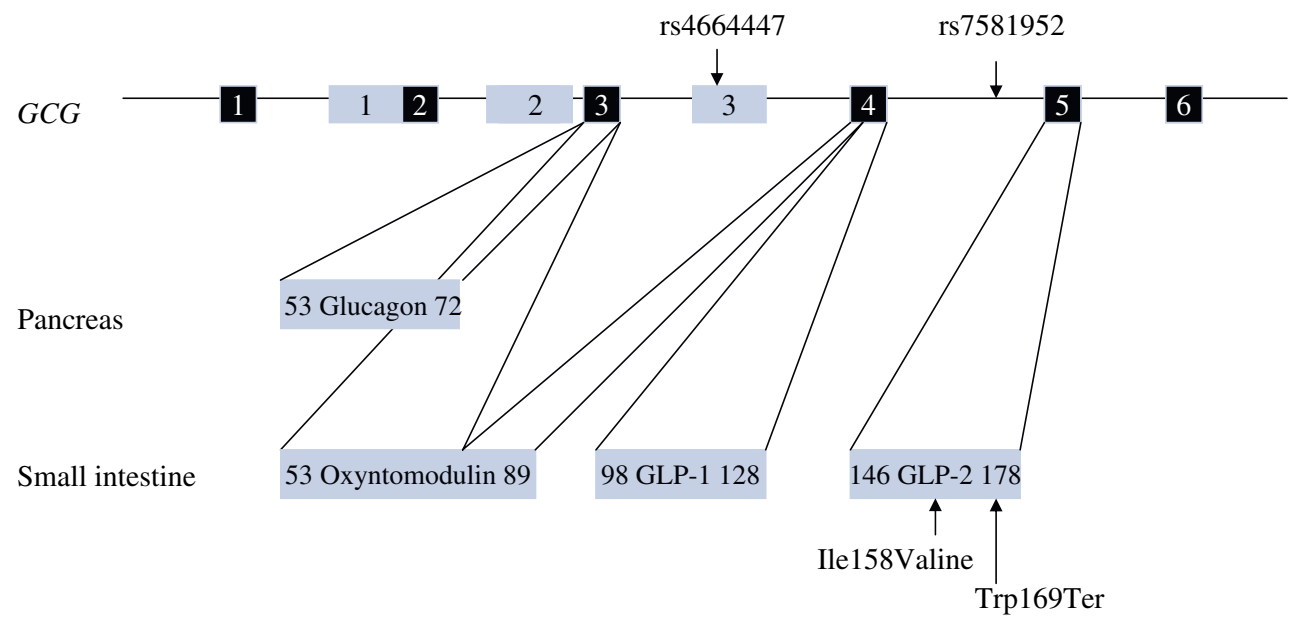

Fig. 1 Genomic structure of $G C G$ and simplified processing of proglucagon hormones. Top: black boxes are exons and grey boxes are conserved inter-exon regions. Bottom: numbers refer to amino acid number in the proglucagon peptide before cleavage, counting from amino acid no. 1 in the signal peptide. Post-translational

OGTT, performed 10 years after the baseline investigation, the AUC for plasma GLP-1 was significantly lower among three homozygous carriers compared with nine matched wild-type carriers $(730 \pm 69$ vs $1,334 \pm 288 \mathrm{pmol} / 1 \times \min , p=$ 0.0002) (Fig. 2). During a glucose-dependent arginine stimulation test, performed 10 years after the baseline investigation, the AUCs for fully processed glucagon during fasting and during the clamps at 14 and $25 \mathrm{mmol} / \mathrm{l}$ glucose were significantly lower for the three homozygous variant carriers compared with nine matched wild-type carriers processing of proglucagon in the pancreas by prohormone convertase (PC) 2 yields glucagon, whereas processing in the intestine by PC1 liberates oxyntomodulin, GLP-1 and GLP-2. The approximate locations of genotyped variants are shown with arrows

Table 2 Case-control studies of type 2 diabetes in relation to the Ile158Val, rs4664447, and rs 7581952 variants in $G C G$

\begin{tabular}{|c|c|c|c|c|c|c|c|}
\hline$G C G$ variant & $n$ (men/women) & $\begin{array}{l}\text { Genotype distribution } \\
\mathrm{Wt} / \mathrm{He} / \mathrm{Ho}(\%)\end{array}$ & MAF (\%) $(95 \% \mathrm{CI})$ & OR $(95 \% \mathrm{CI})$ & $p_{\text {add }}$ & $p_{\text {dom }}$ & $p_{\text {rec }}$ \\
\hline Ile158Val & & IleIle/IleVal/ValVal & & & & & \\
\hline $\begin{array}{l}\text { Glucose-tolerant } \\
\text { individuals }\end{array}$ & $4,768(2,216 / 2,552)$ & $4,750 / 18 / 0(99.6 / 0.4 / 0)$ & $0.2(0.1,0.3)$ & & & & \\
\hline Patients with T2D & $3,641(2,167 / 1,474)$ & $3,618 / 22 / 1(99.3 / 0.6 / 0)$ & $0.3(0.2,0.5)$ & $1.83(1.05,3.9)$ & 0.04 & 0.03 & \\
\hline rs4664447 & & AA/GA/GG & & & & & \\
\hline $\begin{array}{l}\text { Glucose-tolerant } \\
\text { individuals }\end{array}$ & $4,882(2,253 / 2,629)$ & $4,657 / 221 / 4(95.4 / 4.5 / 0.1)$ & $2.3(2.1,2.7)$ & & & & \\
\hline Patients with T2D & $3,525(2,089 / 1,436)$ & $3,358 / 161 / 6(95.3 / 4.6 / 0.2)$ & $2.5(2.1,2.8)$ & $1.05(0.85,1.28)$ & 0.7 & 0.8 & 0.3 \\
\hline rs7581952 & & $\mathrm{TT} / \mathrm{TG} / \mathrm{GG}$ & & & & & \\
\hline $\begin{array}{l}\text { Glucose-tolerant } \\
\text { individuals }\end{array}$ & $4,825(2,243 / 2,582)$ & $4,606 / 221 / 2(95.4 / 4.6 / 0)$ & $2.3(2,2.7)$ & & & & \\
\hline Patients with T2D & $3,491(2,073 / 1,418)$ & $3,326 / 161 / 0(95.3 / 4.6 / 0.1)$ & $2.4(2.1,2.8)$ & $1.04(0.84,1.28)$ & 0.7 & 0.8 & 0.2 \\
\hline
\end{tabular}

Data are number of individuals (men/women), divided into genotype groups ( $\%$ in each group), frequencies of the minor allele (MAF) as percentages $(95 \% \mathrm{CI})$ and ORs $(95 \% \mathrm{CI})$. Differences in genotype distribution were evaluated using logistic regression. $p$ values were adjusted for age, BMI and sex. The OR is calculated for the dominant model (wild-type [Wt] vs heterozygote [He]+homozygote [Ho]). Case-control studies of type 2 diabetes (T2D) were carried out in 3,778 type 2 diabetes patients (1,820 patients recruited at Steno Diabetes Center, 340 patients from the Inter99 cohort, and 1,618 patients from the Danish ADDITION study) and 5,043 glucose-tolerant participants (521 individuals recruited at Steno Diabetes Center and 4,522 individuals from Inter99). The actual number of individuals successfully genotyped for each variant is given in the table

$p_{\text {add }}, p_{\text {dom }}, p_{\text {rec }}, p$ values for additive, dominant and recessive models, respectively 
Table 3 Associations of rs4664447 in $G C G$ with metabolic traits in treatment-naive individuals from the Inter99 cohort

\begin{tabular}{|c|c|c|c|c|c|c|c|}
\hline Rs4664447 & $\mathrm{AA}$ & $\mathrm{AG}$ & GG & Estimates $_{\text {rec }}(95 \%$ CI $)$ & $p_{\text {add }}$ & $p_{\text {dom }}$ & $p_{\text {rec }}$ \\
\hline Alleles (men/women) & $5,495(2,723 / 2,772)$ & $261(126 / 135)$ & $4(3 / 1)$ & & & & \\
\hline Age (years) & $46.1 \pm 7.9$ & $47.0 \pm 8.5$ & $43.9 \pm 7.6$ & & & & \\
\hline Height (cm) & $172.3 \pm 9.2$ & $172.0 \pm 9.4$ & $165.3 \pm 10.5$ & $-11(-17,-4.4)$ & 0.4 & 0.7 & 0.0009 \\
\hline Weight $(\mathrm{kg})$ & $78.1 \pm 16$ & $77.3 \pm 16.2$ & $63.6 \pm 13.4$ & $-18.1(-4.2,-32.0)$ & 0.2 & 0.3 & 0.01 \\
\hline BMI $\left(\mathrm{kg} / \mathrm{m}^{2}\right)$ & $26.2 \pm 4.5$ & $26.1 \pm 4.9$ & $23.2 \pm 3.1$ & $-3.2(-7.5,1.2)$ & 0.4 & 0.5 & 0.2 \\
\hline Waist circumference $(\mathrm{cm})$ & $86.4 \pm 13.2$ & $86.3 \pm 13.1$ & $79.8 \pm 7.9$ & $-9.4(-21,1.7)$ & 0.6 & 0.7 & 0.09 \\
\hline Serum insulin $0 \mathrm{~min}(\mathrm{pmol} / \mathrm{l})$ & $41.8 \pm 27.8$ & $42.6 \pm 28.1$ & $22.3 \pm 14.1$ & $-0.61(-1.2,-0.034)$ & 0.9 & 0.9 & 0.04 \\
\hline Serum insulin $30 \mathrm{~min}(\mathrm{pmol} / \mathrm{l})$ & $290.0 \pm 183$ & $298.3 \pm 197.6$ & $159.3 \pm 83.2$ & $-0.58(-1.1,-0.034)$ & 0.9 & 0.7 & 0.01 \\
\hline Serum insulin $120 \mathrm{~min}(\mathrm{pmol} / \mathrm{l})$ & $216.7 \pm 210.9$ & $218.2 \pm 216.6$ & $95 \pm 22.2$ & $-0.44(-1.2,0.34)$ & 0.6 & 0.6 & 0.3 \\
\hline Plasma glucose $0 \mathrm{~min}(\mathrm{mmol} / \mathrm{l})$ & $5.5 \pm 0.8$ & $5.6 \pm 0.7$ & $4.8 \pm 1.2$ & $-0.16(-0.27,-0.054)$ & 0.7 & 0.4 & 0.004 \\
\hline Plasma glucose $30 \mathrm{~min}(\mathrm{mmol} / \mathrm{l})$ & $8.7 \pm 1.9$ & $8.8 \pm 1.9$ & $9.4 \pm 2.1$ & $0.073(-0.12,0.27)$ & 0.5 & 0.6 & 0.5 \\
\hline Plasma glucose $120 \mathrm{~min}(\mathrm{mmol} / \mathrm{l})$ & $6.21 \pm 2.14$ & $6.27 \pm 1.94$ & $5.12 \pm 0.85$ & $-0.13(-0.42,0.16)$ & 0.8 & 0.8 & 0.4 \\
\hline HOMA-IR & $10.6 \pm 8.0$ & $10.9 \pm 8.0$ & $5.0 \pm 4.1$ & $-0.77(-1.4,-0.15)$ & 0.9 & 0.8 & 0.01 \\
\hline Matsuda's insulin sensitivity & $9.0 \pm 5.7$ & $8.8 \pm 5.4$ & $15.9 \pm 6.5$ & $0.68(0.097,1.3)$ & 0.8 & 0.7 & 0.02 \\
\hline Insulinogenic index & $29.2 \pm 19.4$ & $29.8 \pm 21.3$ & $15.0 \pm 9.8$ & $-0.63(-1.2,-0.022)$ & 0.8 & 1.0 & 0.04 \\
\hline Disposition index & $3.6 \pm 2.8$ & $3.7 \pm 3.1$ & $4.5 \pm 4.3$ & $0.15(-0.58,0.88)$ & 0.8 & 0.8 & 0.7 \\
\hline
\end{tabular}

Data are mean \pm SD

$p$ values were shown for an additive ( $\left.p_{\text {add }}\right)$ (AA vs AG vs GG), dominant ( $\left.p_{\text {dom }}\right)(\mathrm{AA}$ vs $\mathrm{AG}+\mathrm{GG})$ and a recessive model $\left(p_{\text {rec }}\right)(\mathrm{AA}+\mathrm{AG}$ vs GG) (wild-type+heterozygote vs homozygote). Calculated $p$ values were adjusted for sex, age and BMI (when appropriate). Insulin and glucose values were $\log _{10}$ transformed before analysis

variant had decreased height and body weight (Table 5). GCG rs4664447 was not associated with estimates of BMI-defined obesity (ESM Table 1). No meta-analysis data according to a recessive genetic model were available from the MetaAnalyses of Glucose and Insulin Related Traits Consortium (MAGIC) [19]. The variant was not associated with fasting plasma glucose $(p=0.8)$, fasting serum insulin $(p=0.6)$ or HOMA-IR $(p=0.4)$ in meta-analysis data from MAGIC [19] analysed in an additive model. The variant failed a cohort-

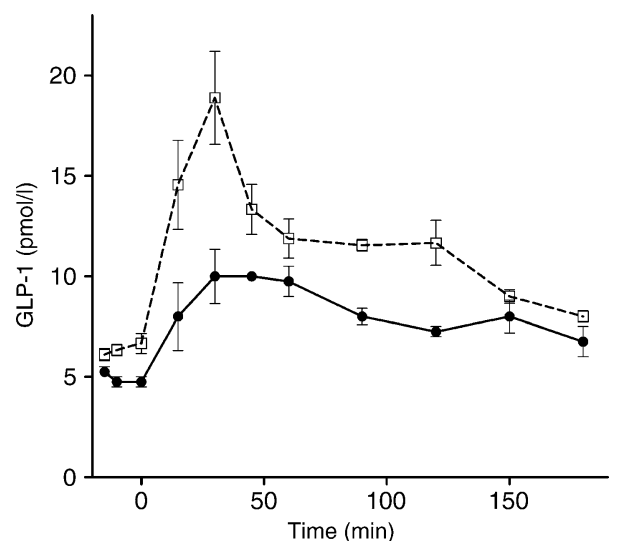

Fig. 2 Plasma GLP-1 levels during an OGTT. Black circles: mutation carriers (rs4664447 GG), $n=3$; white squares: non-mutation carriers (rs4664447 AA) who are BMI, age and sex matched controls (wildtypes), $n=9 . p_{\mathrm{AUC}}=0.0002$ specific quality check in the Diabetes Genetics Replication And Meta-analysis Consortium (DIAGRAM+) [20] analyses.

The $158 \mathrm{Val}$ variant was associated with a higher risk of type 2 diabetes, OR 1.83 (95\% CI 1.05, 3.9), $p=0.03$ (Table 2). The statistical power with 4,768 controls and 3,641 cases was $80 \%$ to detect an OR of 1.83 for this variant (MAF of $0.03 \%$ ) (CaTS power calculator). Heterozygous carriers of $158 \mathrm{Val}$ tended to have lower fasting serum insulin and insulinogenic index $(p=0.06)$, and lower weight $(p=0.01)$ when analysed in 5,795 middle-aged people from Inter99 (Table 6). Ile158Val was not associated with measures of BMI-defined obesity (ESM Table 1). We were unable to associate the $158 \mathrm{Val}$ variant with type 2 diabetes in DIAGRAM+ [20], since this variant was not genotyped or imputed in DIAGRAM+ [20]. There were, however, no significant differences in functional receptor analyses and in intestinotrophic effect analyses between the actions of wild-type GLP-2 and [Ile158Val]-GLP-2 (ESM Fig. 1, ESM Table 2 and ESM Methods).

$G C G$ rs 7581952 was not associated with BMI-defined obesity when examined in a case-control study of 10,223 individuals (ESM Table 1) or with BMI in 5,761 treatmentnaive people in the Inter99 Study (Table 7). However, in the total group of 17,557 individuals, carriers of the minor $\mathrm{G}$ allele of $G C G$ rs7581952 had lower values of BMI, body weight and waist circumference as compared with $\mathrm{T}$ allele carriers when analysed applying a dominant and additive genetic model (Table 5). In an attempt to replicate these 
a
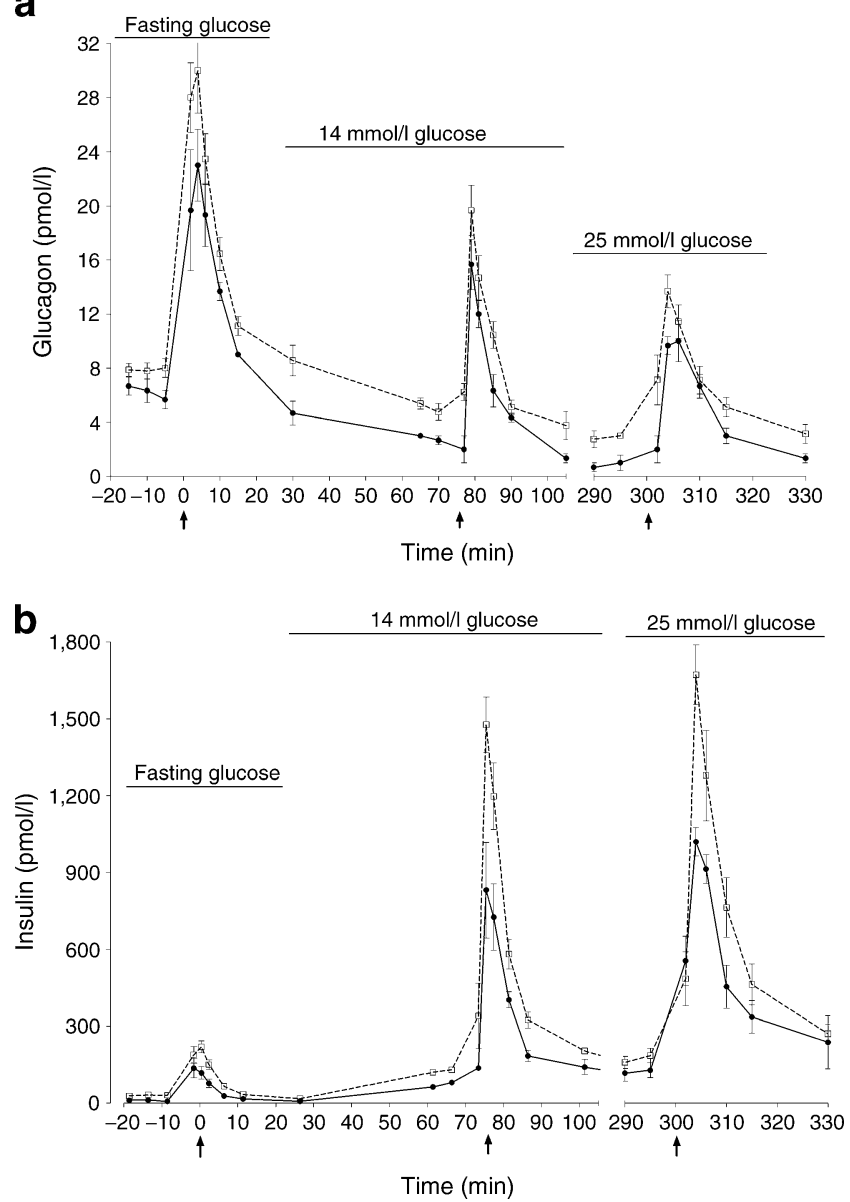

Fig. 3 Fully processed plasma glucagon and serum insulin levels during a glucose-dependent arginine stimulation test. a Fully processed plasma glucagon levels, $p_{\mathrm{AUC}}=0.0004$. b Serum insulin levels, $p_{\mathrm{AUC}}=0.007$. Black circles: mutation carriers (rs4664447 GG), $n=3$; white squares: non-mutation carriers (rs4664447 AA) who are BMI, age and sex matched controls (wild-types), $n=9$. The blood glucose was stabilised and maintained at 14 and $25 \mathrm{mmol} / \mathrm{l}$ for $45 \mathrm{~min}$ prior to and $30 \mathrm{~min}$ after arginine injection (arrow). Blood samples were drawn at $-15,-10,-5,+2,+4,+6,+10,+15$, and +30 min relative to arginine injection. There was a $2.5 \mathrm{~h}$ resting period without glucose infusion in between the clamps at 14 and $25 \mathrm{mmol} / 1$ glucose

observations, rs7581952 was analysed using GIANT metaanalysis data [21]. rs7581952 was not significantly associated with decreased BMI when analysed with an additive model in 100,734 individuals (change in BMI per additional $\mathrm{G}$ allele $-0.03 \mathrm{~kg} / \mathrm{m}^{2}$ (SE 0.02), $p=0.2$; GIANT consortium). The variant failed a cohort-specific quality check in DIAGRAM.

GCG Trp169Ter was initially identified in heterozygous form in one person from the study population for mutation detection in study group 4: onset of diabetes before the age of 40 years and with a family history of diabetes (Table 1). The family members of the carrier were genotyped for the variant. No co-segregation of the variant with diabetes or with measures of obesity was observed (ESM Fig. 2).
Furthermore, subsequently the variant was genotyped in the large Danish sample of 17,584 people and was found in one glucose-tolerant person (age 48 years, BMI $29.4 \mathrm{~kg} / \mathrm{m}^{2}$ ) with a distant family history of diabetes (the grandmother on the father's side and three of the father's ten siblings had diabetes); however, no DNA was available from the family members.

\section{Discussion}

The outcome of the present study of variation in an obvious biological candidate gene, $G C G$, known to be involved in multiple steps of metabolism, suggests that homozygous carriers of the $\mathrm{G}$ allele of the low frequency $G C G$ variant, rs4664447, exhibit several altered metabolic traits. Thus, homozygous carriers have $~ 50 \%$ of the serum insulin levels in the fasting state and following an oral glucose challenge, and lower fasting plasma glucose and height as compared with A allele carriers. The intronic rs4664447 is located in the binding site of the splice enhancer serine/arginine-rich splicing factor 1 isoform 2 (SF2/ASF), which interacts with the spliceosome and ensures the accuracy of splicing. Based upon in silico estimation, the variant is predicted to disrupt this essential binding site, and is estimated to have high functionality (risk 4 on a scale of $0-5$ ). Furthermore, the A allele is conserved among species and the variant is positioned in a conserved region. We hypothesised that the variant decreases the expression of $G C G$ as a result of splicing errors, resulting in low circulating glucagon and GLP-1 levels. Therefore, we re-invited the homozygous carriers of this variant and matched control individuals for an additional OGTT and a combined glucose and arginine stimulation test. The new investigations took place 10 years after the first OGTT in these volunteers. Indeed, we found that homozygous carriers of the rare $\mathrm{G}$ allele of rs 4664447 had approximately half the fasting and stimulated circulating levels of GLP-1, glucagon and insulin compared with matched wild-type carriers. The GG carriers had increased insulin sensitivity as calculated by HOMA-IR and Matsuda's index, respectively, while the disposition index was similar between the genotype groups. Thus, although GG carriers had severely decreased fasting and stimulated serum insulin levels, the insulin response was adequate for the level of insulin sensitivity, indicating a normal beta cell function with retained capacity to adapt to changes in insulin sensitivity. This interpretation of data also corresponds with the lack of an association of the variant with type 2 diabetes. Rather, the low serum insulin levels in the homozygous carriers may be viewed as a compensatory mechanism resulting from the low levels of glucagon. Indeed, it has been shown that endogenously released glucagon may determine the cAMP production in beta cells 
Table 4 Associations of rs4664447 in $G C G$ with metabolic traits during glucose-dependent arginine stimulation test

\begin{tabular}{|c|c|c|c|}
\hline rs4664447 & AA & GG & $p$ value \\
\hline Participants (men/women) & $9(6 / 3)$ & $3(2 / 1)$ & \\
\hline Age (year) & $54 \pm 7$ & $55 \pm 9$ & \\
\hline BMI $\left(\mathrm{kg} / \mathrm{m}^{2}\right)$ & $24.7 \pm 3.3$ & $24.2 \pm 3.1$ & 0.2 \\
\hline Serum insulin $0 \mathrm{~min}(\mathrm{pmol} / \mathrm{l})$ & $27 \pm 8$ & $11 \pm 4$ & 0.002 \\
\hline Plasma glucose $0 \mathrm{~min}(\mathrm{mmol} / \mathrm{l})$ & $5.9 \pm 0.5$ & $5.6 \pm 0.5$ & 0.5 \\
\hline HOMA-IR & $7.2 \pm 2.7$ & $2.6 \pm 1.8$ & 0.002 \\
\hline Fasting $\mathrm{AIR}_{0-10 \text { arginine }}(\mathrm{pmol} / 1 \times \min )$ & $2,208 \pm 501$ & $1,265 \pm 157$ & 0.0006 \\
\hline Clamp $14 \mathrm{mmol} / 1$ glucose $\mathrm{AIR}_{0-10 \text { arginine }}(\mathrm{pmol} / 1 \times \min )$ & $9,636 \pm 3,370$ & $6,118 \pm 1,600$ & 0.04 \\
\hline Clamp $25 \mathrm{mmol} / 1$ glucose $\mathrm{AIR}_{0-10 \text { arginine }}(\mathrm{pmol} / 1 \times \min )$ & $11,510 \pm 3,562$ & $7,592 \pm 916$ & 0.02 \\
\hline Disposition index (fasting $\mathrm{AIR}_{0-10 \text { arginine }} / \mathrm{HOMA}-\mathrm{IR}$ ) & $357 \pm 157$ & $558 \pm 321$ & 0.4 \\
\hline
\end{tabular}

Data are mean \pm SD

$\mathrm{AIR}_{0-10 \text { arginine }}$ is the AIR following arginine stimulation $(0-10 \mathrm{~min})$

and thereby the insulin secretion [22]. The low fasting plasma glucose can also directly be explained by the decreased circulating glucagon levels causing decreased glycogenolysis and gluconeogenesis. In agreement with this concept, the $G C G$ knockout mouse manifests with lower blood glucose and lower serum insulin levels, as well as higher insulin sensitivity, compared with wild-type mice
[23]. The lower height among homozygous carriers compared with wild-type carriers may be due to the low serum insulin levels with reduced anabolic effects of insulin, probably starting in the fetus. It should be noted that the potential functionality of the intronic rs 4664447 is predicted based on bioinformatics analysis and in vivo physiological associations. Obviously, future studies should attempt to validate

Table 5 Anthropometric data stratified on Ile158Val, rs4664447 and rs7581952 of GCG in the combined study sample of 17,584 Danes

\begin{tabular}{lllllll}
\hline$G C G$ variant & Participants (men/women) & Age (years) & BMI $\left(\mathrm{kg} / \mathrm{m}^{2}\right)$ & Body weight $(\mathrm{kg})$ & Waist circumference $(\mathrm{cm})$ & Height $(\mathrm{cm})$ \\
\hline Ile158Val & & & & & & \\
Ilelle & $17,320(9,190 / 8,130)$ & $55 \pm 11$ & $27.8 \pm 5$ & $82 \pm 17$ & $93 \pm 15$ & $171 \pm 9$ \\
IleVal & $69(33 / 36)$ & $57 \pm 11$ & $27.8 \pm 4.1$ & $80 \pm 13$ & $93 \pm 13$ & $170 \pm 8$ \\
ValVal & $2(2 / 0)$ & $58 \pm 14$ & $33.6 \pm 6.4$ & $103 \pm 24$ & $114 \pm 19$ & $174 \pm 4$ \\
$p_{\text {dom }}$ & & & 0.8 & 0.7 & 0.9 & 0.2 \\
rs4664447 & & & & & $171 \pm 9$ \\
AA & $16,771(8,879 / 7,892)$ & $55 \pm 11$ & $27.8 \pm 5$ & $82 \pm 17$ & $93 \pm 15$ & $171 \pm 10$ \\
GA & $797(413 / 384)$ & $55 \pm 11$ & $27.6 \pm 5.2$ & $81 \pm 17$ & $92 \pm 15$ & $168 \pm 9$ \\
GG & $14(10 / 4)$ & $54 \pm 15$ & $26.7 \pm 6.8$ & $71 \pm 16$ & $94 \pm 18$ & 0.1 \\
$p_{\text {add }}$ & & & 0.2 & 0.02 & 0.02 & 0.2 \\
$p_{\text {dom }}$ & & 0.2 & 0.04 & 0.02 & 0.003 \\
$p_{\text {rec }}$ & & & 0.4 & 0.004 & 0.8 & $171 \pm 9$ \\
rs7581952 & & & & & $171 \pm 10$ \\
TT & $16,754(8,910 / 7,844)$ & $55 \pm 11$ & $27.8 \pm 5.1$ & $82 \pm 17$ & $94 \pm 15$ & $170 \pm 8$ \\
TG & $792(415 / 377)$ & $55 \pm 11$ & $27.5 \pm 5.0$ & $81 \pm 17$ & $92 \pm 15$ & 0.4 \\
GG & $11(6 / 5)$ & $58 \pm 17$ & $26.4 \pm 5.8$ & $76 \pm 16$ & $93 \pm 16$ & 0.5 \\
$p_{\text {add }}$ & & & 0.04 & 0.03 & 0.009 & 0.3 \\
$p_{\text {dom }}$ & & 0.04 & 0.03 & 0.009 & \\
$p_{\text {rec }}$ & & & 0.3 & 0.2 & 0.6 & \\
\hline
\end{tabular}

Data are mean \pm SD

The actual number of individuals genotyped for each variant is stated in the table

$p$ values were calculated for additive $\left(p_{\text {add }}\right)$, dominant $\left(p_{\text {dom }}\right)$, and recessive models $\left(p_{\text {rec }}\right)$, except for Ile158Val, which only could be calculated in a dominant model due to low frequency. Adjustments were made for the effect of age and sex 
Table 6 Associations of Ile158Val in $G C G$ with metabolic traits in treatment-naive individuals from the Inter99 cohort

Data are mean $\pm \mathrm{SD}$

$p$ values were only possible to calculate for a dominant model $\left(p_{\text {dom }}\right)$. Calculated $p$ values were adjusted for sex, age and BMI (when appropriate). Insulin and glucose values were $\log _{10}$ transformed before analysis

\begin{tabular}{llll}
\hline Ile158Val & IleIle & IleVal & $p_{\text {dom }}$ \\
\hline Alleles (men/women) & $5,785(2,724 / 3,061)$ & $20(12 / 8)$ & \\
Age (years) & $46.1 \pm 7.9$ & $45.7 \pm 7.2$ & \\
Height (cm) & $172 \pm 9$ & $173 \pm 9$ & 0.4 \\
Weight (kg) & $78.1 \pm 16$ & $74.8 \pm 10.6$ & 0.01 \\
BMI (kg/m ${ }^{2}$ ) & $26.2 \pm 4.6$ & $25.2 \pm 3.3$ & 0.3 \\
Waist circumference (cm) & $86.6 \pm 13.4$ & $84.7 \pm 8.8$ & 0.2 \\
Serum insulin 0 min (pmol/1) & $42.9 \pm 29.8$ & $34.8 \pm 22.2$ & 0.06 \\
Serum insulin 30 min (pmol/l) & $290.5 \pm 183.8$ & $230.6 \pm 123.4$ & 0.1 \\
Serum insulin 120 min (pmol/1) & $217.6 \pm 213.0$ & $158.2 \pm 77.9$ & 0.6 \\
AUC for insulin (pmol/l) & $22,917 \pm 15,962$ & $16,687 \pm 7,979$ & 0.06 \\
Plasma glucose 0 min (mmol/l) & $5.6 \pm 1.1$ & $5.8 \pm 2.2$ & 0.6 \\
Plasma glucose 30 min (mmol/l) & $8.7 \pm 1.9$ & $9.1 \pm 3.1$ & 0.6 \\
Plasma glucose 120 min (mmol/l) & $6.2 \pm 2.1$ & $6.8 \pm 4.2$ & 0.4 \\
HOMA-IR & $11.1 \pm 10.0$ & $9.3 \pm 7.1$ & 0.1 \\
Matsuda's insulin sensitivity & $9.0 \pm 5.6$ & $9.5 \pm 4.5$ & 0.3 \\
Insulinogenic index & $29.2 \pm 19.6$ & $22.8 \pm 11.5$ & 0.06 \\
Disposition index & $3.6 \pm 2.8$ & $3.8 \pm 3.0$ & 0.7 \\
\hline
\end{tabular}

these findings in appropriate in vitro assays. We attempted to replicate these findings by applying a recessive genetic model in DIAGRAM+ and in MAGIC meta-analyses. However, both DIAGRAM and MAGIC only provide meta-analysis data from additive models. Furthermore, in DIAGRAM the variant failed a cohort-specific quality check; this is likely to be the case for several low frequency variants. In accordance with our findings using an additive model, there were no significant additive associations in MAGIC, because only the phenotypes of homozygous carriers of the low frequency $G$ allele were different from AA and AG carriers.
Carriers of the Val allele of the Ile158Val variant had nearly twice as high a risk of type 2 diabetes as compared with Ile allele carriers. However, as the association of Ile158Val with type 2 diabetes is borderline significant, it would not pass any correction for multiple testing. Therefore we performed functional analyses of this mutant GLP-2 peptide. However, both in functional receptor analyses and in intestinotrophic effect analyses, there was no significant difference between the properties of wild-type GLP-2 and [Ile158Val]-GLP-2. Thus, we consider the association between Ile158Val and type 2 diabetes as a chance finding.
Table 7 Associations of rs7581952 in $G C G$ with metabolic traits in treatmentnaive individuals from the Inter99 cohort

Data are mean \pm SD

$p$ values were only possible to calculate for a dominant model $\left(p_{\text {dom }}\right)$. Calculated $p$ values were adjusted for sex, age and BMI (when appropriate). Insulin and glucose values were $\log _{10}$ transformed before analysis

\begin{tabular}{lllll}
\hline rs7581952 & TT & TG & GG & $p_{\text {dom }}$ \\
\hline Alleles (men/women) & $5,494(2,720 / 2,774)$ & $265(130 / 135)$ & $2(1 / 1)$ & \\
Height (cm) & $172 \pm 9$ & $172 \pm 10$ & $171 \pm 10$ & 0.8 \\
Weight (kg) & $78.1 \pm 16$ & $77.6 \pm 16.1$ & $77.7 \pm 0.7$ & 0.5 \\
BMI (kg/m ${ }^{2}$ ) & $26.2 \pm 4.5$ & $26.0 \pm 4.7$ & $25.7 \pm 3.5$ & 0.5 \\
Waist circumference (cm) & $86 \pm 13$ & $86 \pm 12.82$ & $85 \pm 2.8$ & 0.9 \\
Serum insulin 0 min (pmol/1) & $41.8 \pm 27.8$ & $42.6 \pm 27.6$ & $24 \pm 12.7$ & 0.7 \\
Serum insulin 30 min (pmol/1) & $289.4 \pm 178.7$ & $296.4 \pm 191.5$ & $140.5 \pm 47.3$ & 0.6 \\
Serum insulin 120 min (pmol/l) & $216.8 \pm 211.2$ & $214.7 \pm 209.9$ & $98 \pm 8.4$ & 0.8 \\
AUC for insulin (pmol/l) & $22,853 \pm 15,716$ & $23,166 \pm 15,247$ & $10,320 \pm 1,887$ & 0.7 \\
Plasma glucose 0 min (mmol/1) & $5.5 \pm 0.8$ & $5.6 \pm 0.7$ & $5.2 \pm 0.5$ & 0.2 \\
Plasma glucose 30 min (mmol/1) & $8.6 \pm 1.8$ & $8.7 \pm 1.9$ & $7.8 \pm 0.4$ & 0.9 \\
Plasma glucose 120 min (mmol/1) & $6.2 \pm 2.1$ & $6.2 \pm 1.8$ & $5.1 \pm 1.0$ & 0.6 \\
HOMA-IR & $10.5 \pm 7.9$ & $10.8 \pm 7.9$ & $5.3 \pm 2.3$ & 0.5 \\
Matsuda's insulin sensitivity & $9.0 \pm 5.6$ & $8.9 \pm 5.4$ & $15.9 \pm 6.4$ & 0.7 \\
Insulinogenic index & $29.2 \pm 19.0$ & $29.8 \pm 21.0$ & $15.01 \pm 5.36$ & 0.4 \\
Disposition index & $3.6 \pm 2.8$ & $3.7 \pm 3.1$ & $3.8 \pm 3.9$ & 0.7 \\
\hline
\end{tabular}


The phenotype of carriers of the $\mathrm{G}$ allele of $G C G$ rs7581952 was characterised by lower BMI, body weight, and waist circumference as compared with $\mathrm{T}$ allele carriers. The BMI was decreased by 1.4 BMI units for GG allele carriers compared with TT allele carriers in 17,557 Danes. We attempted to replicate the findings of decreased BMI for GG carriers. However, in the GIANT meta-analysis there was no significant additive decreased BMI for $\mathrm{G}$ allele carriers. Thus, we conclude that our initial findings are spurious.

The Trp169Ter variant did not co-segregate with measures of obesity or diabetes although the mutation causes a transcriptional termination of nine amino acids from the Cterminal end of GLP-2. This will properly disrupt the action of the peptide. As the mutation was found in the heterozygous form only and no obvious phenotype was seen, one normal allele may be sufficient for synthesis of adequate amounts of GLP-2 to obtain its normal physiological function.

We did not find any presumably functional $G C G$ mutation that co-segregated with early-onset nonautoimmune diabetes or early-onset obesity, suggesting that the $G C G$ variants discovered may not be involved in the pathogenesis of monogenic forms of diabetes or obesity. This indicates that genetic variation in $G C G$ will have no major impact on clinical practice.

Our study has limitations. One is that the variants that were chosen for the large-scale association studies were selected based on in silico information in combination with phenotypes of carriers, which leaves the possibility that non-selected variants also associate with metabolic traits.

Second, even though the statistical power to detect the large differences in circulating insulin, GLP-1 and glucagon levels between $G C G$ rs 4664447 variant carriers was above $80 \%$, it was only possible to perform the OGTT and hyperglycaemic arginine stimulation studies in three GG carriers compared with nine AA carriers. This illustrates the difficulties of providing proof of concept of functionality of recessive-acting low frequency variants.

Furthermore, when Bonferroni correction for multiple testing was applied, only $p$ values of 0.001 or less were considered significant. Thus, these suggestive results need to be replicated in independent large-scale studies, where it is possible to apply recessive models on directly genotyped data. At present the relevant GWAS meta-analysis data are not suitable for replication of low frequency variants analysed for recessive models.

In conclusion, if replicated, the present biological candidate gene study in Danish individuals suggests that homozygous minor allele carriers of the low frequency $G C G$ rs4664447 variant have significantly decreased fasting and stimulated circulating levels of insulin, glucagon and GLP-1. Overall, our findings suggest that variation in $G C G$ has no major impact on carbohydrate metabolism in the study populations examined.
Acknowledgements We are most grateful to M. McCarthy and A. Morris representing the DIAGRAM+ consortium, and J. Florez, I. Barroso and E. Wheeler representing MAGIC, who kindly provided us with information about $G C G$ genotype information from metaanalyses data.This study has been orally presented at the 46th Annual Meeting of the EASD, Stockholm, 20-24 September 2010. We are grateful to the participating patients. From the Hagedorn Research Institute, we thank A. Forman, T. Lorentzen and M. Stendal for technical assistance, A. Nielsen for data management, G. Lademann for secretarial support and T. Boesgaard and T. Sparsø for scientific discussions. From the Department of Biomedical Sciences, University of Copenhagen, we thank S. Pilgaard and L. Albæk for technical assistance. The research was supported by grants from the Danish Research Council, the Lundbeck Foundation Centre of Applied Medical Genomics for Personalized Disease Prediction, Prevention and Care, the University of Copenhagen, the Czech research project of MSM VZ No. 0021620814 and the University Investment Capital (UNIK): Food, Fitness \& Pharma for Health and Disease from the Danish Ministry of Science, Technology and Innovation.

Contribution statement SST was responsible for the conception and design, analysis and interpretation of data, drafting the article, revising it critically for important intellectual content and final approval of the version to be published. $\mathrm{LM}, \mathrm{NG}, \mathrm{BH}, \mathrm{HK}, \mathrm{MR}$ and the GIANT Consortium were responsible for analysis and interpretation of data, revising the article critically for important intellectual content and final approval of the version to be published. IAH, UK, JL, DRW, TJ, AS, TL, ODM, JW and AL were responsible for conception and design, revising the article critically for important intellectual content and final approval of the version to be published. $\mathrm{SM}, \mathrm{JJH}, \mathrm{TH}$ and OP were responsible for conception and design, analysis and interpretation of data, revising the article critically for important intellectual content and final approval of the version to be published.

Duality of interest O.D. Madsen and D.R. Witte are employed by and own stock in Novo Nordisk A/S, a pharmaceutical company selling diabetes products.

\section{References}

1. Frazer KA, Ballinger DG, Cox DR et al (2007) A second generation human haplotype map of over 3.1 million SNPs. Nature 449:851-861

2. The International HapMap Consortium (2005) A haplotype map of the human genome. Nature 437:1299-1320

3. Holst JJ (1997) Enteroglucagon. Annu Rev Physiol 59:257-271

4. Nickerson DA, Tobe VO, Taylor SL (1997) PolyPhred: automating the detection and genotyping of single nucleotide substitutions using fluorescence-based resequencing. Nucleic Acids Res $25: 2745-2751$

5. Gordon D, Abajian C, Green P (1998) Consed: a graphical tool for sequence finishing. Genome Res 8:195-202

6. Jørgensen T, Borch-Johnsen K, Thomsen TF, Ibsen H, Glumer C, Pisinger C (2003) A randomized non-pharmacological intervention study for prevention of ischaemic heart disease: baseline results Inter99. Eur J Cardiovasc Prev Rehabil 10:377-386

7. Hainerova I, Torekov SS, Ek J et al (2006) Association between neuromedin $U$ gene variants and overweight and obesity. J Clin Endocrinol Metab 91:5057-5063

8. Yuan HY, Chiou JJ, Tseng WH et al (2006) FASTSNP: an always up-to-date and extendable service for SNP function analysis and prioritization. Nucleic Acids Res 34:W635-W641 
9. Cartegni L, Wang J, Zhu Z, Zhang MQ, Krainer AR (2003) ESEfinder: a web resource to identify exonic splicing enhancers. Nucleic Acids Res 31:3568-3571

10. Sandbaek A, Griffin SJ, Rutten G et al (2008) Stepwise screening for diabetes identifies people with high but modifiable coronary heart disease risk. The ADDITION Study. Diabetologia 51:1127-1134

11. Clausen JO, Borch-Johnsen K, Ibsen H et al (1996) Insulin sensitivity index, acute insulin response, and glucose effectiveness in a population-based sample of 380 young healthy Caucasians. Analysis of the impact of gender, body fat, physical fitness, and life-style factors. J Clin Invest 98:1195-1209

12. Alberti KG, Zimmet P (1998) Definition, diagnosis and classification of diabetes mellitus and its complications. Part 1: diagnosis and classification of diabetes mellitus provisional report of a WHO consultation. Diabet Med 15:539

13. Holst JJ (1983) Molecular heterogeneity of glucagon in normal subjects and in patients with glucagon-producing tumours. Diabetologia 24:359-365

14. Orskov C, Rabenhoj L, Wettergren A, Kofod H, Holst JJ (1994) Tissue and plasma concentrations of amidated and glycineextended glucagon-like peptide I in humans. Diabetes 43:535-539

15. Kielgast U, Asmar M, Madsbad S, Holst JJ (2010) Effect of glucagon-like peptide-1 on alpha- and beta-cell function in Cpeptide-negative type 1 diabetic patients. J Clin Endocrinol Metab 95:2492-2496
16. Pritchard JK, Stephens M, Donnelly P (2000) Inference of population structure using multilocus genotype data. Genetics 155:945-959

17. Price AL, Patterson NJ, Plenge RM, Weinblatt ME, Shadick NA, Reich D (2006) Principal components analysis corrects for stratification in genome-wide association studies. Nat Genet 38:904-909

18. Torekov SS, Larsen LH, Glumer C et al (2005) Evidence of an association between the $\operatorname{Arg} 72$ allele of the peptide YY and increased risk of type 2 diabetes. Diabetes 54:2261-2265

19. Dupuis J, Langenberg C, Prokopenko I et al (2010) New genetic loci implicated in fasting glucose homeostasis and their impact on type 2 diabetes risk. Nat Genet 42:105-116

20. Voight BF, Scott LJ, Steinthorsdottir Vet al (2010) Twelve type 2 diabetes susceptibility loci identified through large-scale association analysis. Nat Genet 42:579-589

21. Speliotes EK, Willer CJ, Berndt SI et al (2010) Association analyses of 249,796 individuals reveal 18 new loci associated with body mass index. Nat Genet 42:937-948

22. Pipeleers DG, Schuit FC, in't Veld PA et al (1985) Interplay of nutrients and hormones in the regulation of insulin release. Endocrinology 117:824-833

23. Hayashi Y, Yamamoto M, Mizoguchi H et al (2009) Mice deficient for glucagon gene-derived peptides display normoglycemia and hyperplasia of islet \{alpha\}-cells but not of intestinal L-cells. Mol Endocrinol 23:1990-1999 